\title{
Fetal anterior neck lump and the patency of airway: The ex-utero intrapartum treatment (EXIT procedure)
}

\author{
Rishard $\mathbf{M}^{1}$, Vithanachchi $\mathrm{K}^{2}$, Gunawardena $\mathrm{K}^{1}$, Dias $\mathbf{T}^{3}$
}

\section{Introduction}

Airway obstruction at birth is a rare medical emergency leading to many catastrophes. Anterior fetal neck lumps can compress or bend the trachea leading to difficulty in initiating spontaneous breathing. Antenatal prediction of degree of air way obstruction is poor as visualization of fetal trachea is often a challenge due to fetal positioning. Presence of polyhydramnios without any other identifiable cause may increase the suspicion of possible air way obstruction. Advances in fetal imaging and availability of multidisciplinary settings have improved the outcome of such babies by planned delivery when airway obstruction is anticipated ${ }^{1}$. The ex-utero intrapartum treatment (EXIT) procedure is a safest and novel technique that has been successfully performed to secure the airway in a controlled manner at the time of delivery $^{2}$. During the EXIT baby is partly delivered by the caesarean section to the maternal pubic area and then the paediatric/anaesthetic resuscitation team secures the air way access while baby is connected to the placenta through the umbilical cord. Excellent maternal and fetal outcome can be achieved if the procedure is performed by the skilled multidisciplinary team ${ }^{3}$. Here we describe the successful case of EXIT in a limited resource setting.

\footnotetext{
${ }^{1}$ Teaching Hospital Kandy, ${ }^{2}$ Provincial Hospital Badulla, ${ }^{3}$ District General Hospital Ampara.

Correspondence: Tiran Dias

E-mail: thiran_dias@yahoo.com
}

\section{Case report}

Mrs B 30 year old gravida 2 para 1 was referred to fetal medicine centre with a suspected neck lump at 23 weeks of pregnancy. She has had an uncomplicated antenatal history and detailed anomaly scan revealed acystic and solid left anterior-lateral neck lump measuring $6 \times 4 \times 5 \mathrm{~cm}^{3}$ in size (Figure 1). This lump was extending from the face up to the thorax of the baby. There was a separate blood supply noted to this lump and provisional diagnosis of teratoma was made. Subsequent follow-up scans showed progressive enlargement of the lump. Degree of airway obstruction/deviation was unable to assess confidently ultra sonically. In order to optimise the condition of the baby at birth a multidisciplinary team consisted of an ENT surgeon, an anaesthetist, a paediatric surgeon was arranged. An uncomplicated EXIT procedure (was) had been performed at 38 weeks.

\section{Description of the procedure}

Eligible cases must be prenatally diagnosed conditions which are at risk of airway obstruction without intervention. Since time taken to secure the airway could vary from simple intubation to tracheostomy, it is important to keep the intact fetomaternal circulation throughout the procedure 4 . Deep general anaesthesia (GA) remains the technique of choice for the EXIT procedure as it relaxes the uterus thus improves the utero placental blood flow ${ }^{1}$. Incision of choice is usually low transverse abdominal incision but can be fashioned as per the need ${ }^{1}$. After delivery of the baby's head an in-utero intubation or tracheostomy, or dissection of the neck is performed while the baby remains on placental support ${ }^{5,6}$. Postpartum haemorrhage is the known complication of EXIT.

An EXIT procedure was performed at the Teaching Hospital, Kandy in the presence of an experienced team comprised of an obstetrician, an

\section{Figure 1. Ultrasound appearance of the neck lump, A-Anterior neck lump, B- Feeding vessel to the lump.}

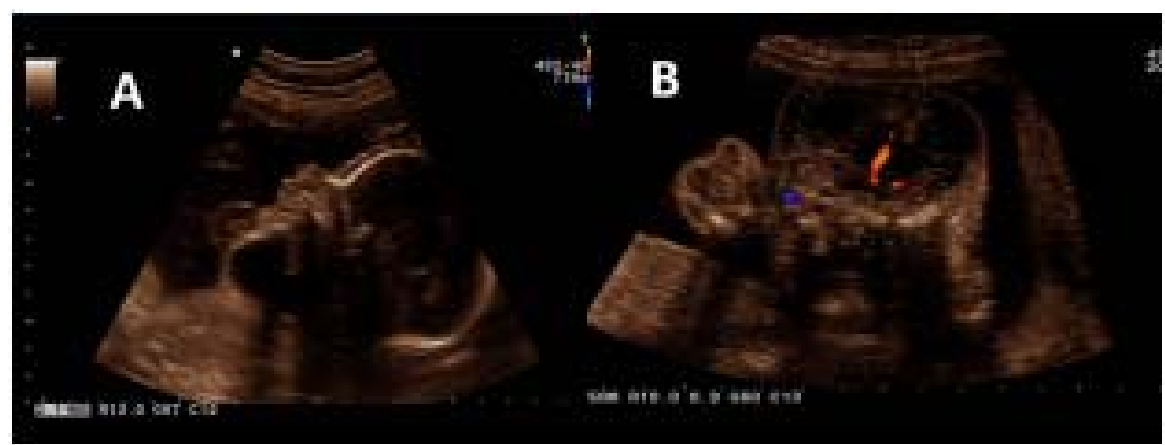


anaesthetist, a paediatric anaesthetist, a paediatric surgeon, an ENT surgeon and a neonatologist. Baby's head was carefully delivered and the neck area was exposed while monitoring the fetal heart rate. Then the direct laryngoscopy and intubation was successfully performed avoiding the need of a tracheostomy or further surgical interventions. The baby was transferred to surgical intensive care unit for further management (Figure 2).

Figure 2. Neck lump after the birth.

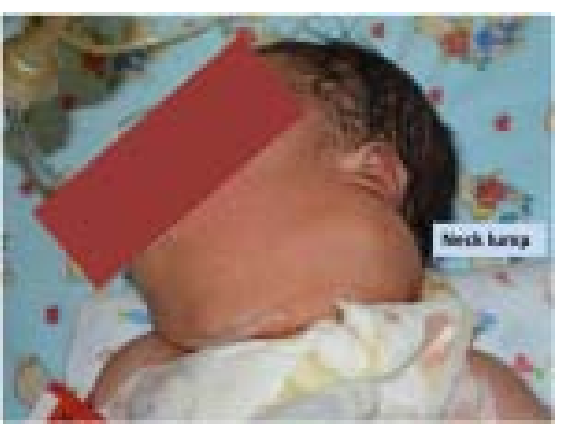

\section{Discussion}

It appears that the EXIT procedure can be safely utilized as a tool to improve the outcome of neonates with potential airway obstruction even in the poor resource settings. Although the EXIT procedures are successfully performed in technically advanced units, our experience suggests that the careful prenatal assessment and orchestration of a multidisciplinary team should be attempted to improve the neonatal outcome which other wise may be dismal. Likelihood of neonatal airway obstruction if delivered by standard caesarean section overweighs the theoretical risks of placental abruption, postpartum haemorrhage due to atony, and uterine lacerations that may happen during the EXIT procedure.

\section{REFERENCES}

1. Marwan A, Crombleholme TM. The EXIT procedure: principles, pitfalls, and progress.
Seminars in Paediatric Surgery 2006; 15 : 107-15.

2. Lazar DA, Olutoye OO, Moise $\mathrm{KJ}$, et al. Ex-utero intrapartum treatment procedure for giant neck masses - fetal and maternal outcomes. Journal of Paediatric Surgery 2011; 46: 817-22.

3. Olutoye OO, Olutoye OA. EXIT procedure for fetal neck masses. Current Opinion in Paediatrics 2012; 24: 386-93.

4. Catalano PJ, Urken ML, Alvarez M. New approach to the management of airway obstruction in "high risk" neonates. Archives of Otolaryngology - Head and Neck Surgery 1992; 118: 306-9.

5. MacKenzie TC, Crombleholme TM, Flake AW. The ex-utero intrapartum treatment. Current Opinion in Pediatrics 2002; 14 : 453-8.

6. Bouchard S, Johnson MP, Flake AW, et al. The EXIT procedure: experience and outcome in 31 cases. Journal of Pediatric Surgery 2002; 37: 418-26. 